\title{
ON A NEW SPECIMEN OF A PALEONISCID BRAIN FROM IOWA \\ by
}

ROY L. MOODIE 



\section{ON A NEW SPECIMEN OF A PALEONISCID BRAIN FROM IOWA}

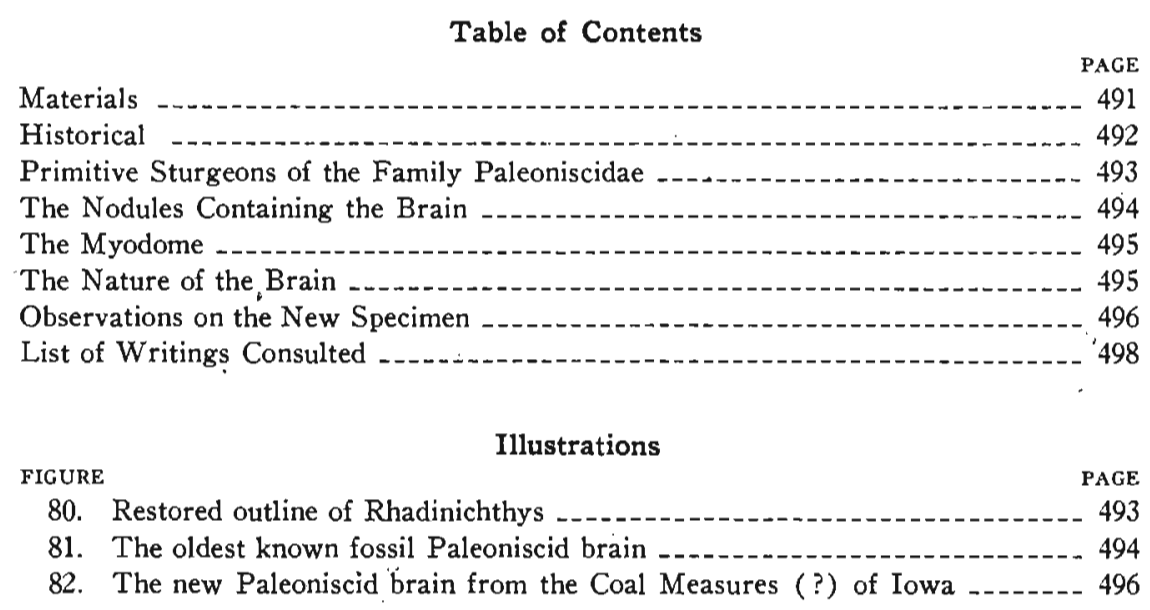

\section{Materials}

A single nodule, about one-half inch in diameter, picked up on the Rock Island railroad tracks in Iowa City by Mr. William Shurtz and handed to Mr. Herbert Belanski of the University staff and by him to Professor A. O. Thomas at the University, forms the basis for this paper. I am under obligations to Professor Thomas for the opportunity to confirm his identification of the fossilized remains enclosed within the nodule as a part of the cartilaginous* brain case, the brain and semicircular canals of a Paleoniscid fish allied to Rhadinichthys. Director G. F. Kay has made the study and publication possible by providing financial aid. Although numerous nodules of this type have been described (see papers by Eastman, Moodie, Parker and Watson) yet the present discovery provides an important new locality for the brain-containing nodules; the nodule itself is split so that the ventral aspect of the brain is more clearly shown than in any of the scores of brain-containing nodules examined from the Coal Measures of Kansas (Moodie, '15, '20); it shows that the brain practically fills the brain-

\footnotetext{
* Watson ('25) states that the endocranium is fully ossified.
} 
case, as Watson ('25) suggested; and it shows something of the braincase. Any one of these features would justify this description.

It has not been thought feasible to attempt any preparation of the fossil, so it remains as it was found. The nodule bears the catalogue number 13-338 of the Department of Geology, University of Iowa. The drawing (figure 82) is from the pen of the experienced artist, Mr. John L. Ridgway, of the California Institute of Technology at Pasadena.

\section{Historical}

I have already given (Moodie, '15) a complete review of the preservation of neural structures, including an annotated bibliography of writings to that date, and there is no need to go over.the grourd so thoroughly covered. It remains to discuss the contributions of Stensiö ('25) and Watson ('25) on brains and brain case, reserving an account of Stensiö's ('21) and Watson's ('28) writings on the organization of the Paleoniscidae for a later section.

No author has added so richly to our knowledge of neural form among Paleozoic and Triassic vertebrates as has Stensiö. It is not necessary here to add an extensive literature list. of Stensiö's ichthyological writings, but I will state that his accounts and illustrations of the brain and nerves of the Upper Silurian (Downtownian) Cephalaspidae and of the Devonian Arthrodire Macropetalichthys are without parallel in the realm of vertebrate paleontology.

In Stensiö's ('25, pages $80-81$, fig. $17 ; 158 ; 176-177$, fig. $57 ; 192$ )' discussions of the family Saurichthyidae, allied to the Paleoniscidae, from the Triassic of Spitsbergen, he says:

"On the whole, the brain of the Saurichthyids was of the Actinopterygian type. The telencephalon must have been of about the same order of size as in ordinary teleosts . . . ." This is very pertinent matter in determining the systematic relationships of the ancient family of Paleoniscids, discussed in the next section.

When Doctor Watson visited the United States I discussed with him the nature of the paleoniscid brains and gave him some nodules which I had collected near Baldwin, Kansas. These nodules later (Watson, '25, p. 832) furnished the basis for Watson's determination of a small, but typical and clearly functional myodome of a thoroughly Actinopterygian type (See Watson's figures 9 to 20). This discovery was possible because the bone and cartilage within the nodules was perfectly 
friable and easily removed with a blunt needle. After the cavity was thoroughly cleaned impressions were made in wax, thus furnishing material for a discussion of the brain case and the myodome, a structure peculiar to fishes, often called the eye-muscle canal, limited to certain teleosts. This is more fully discussed in another section.

\section{The Primitive Sturgeons of the Family Paleoniscidae}

The ganoid fishes of the family Paleoniscidae are of extreme interest to paleontologists because during their long geological history from the Devonian to the Jurassic (Dean, '23, p. 622) they were associated with and were related to the Crossopterygian ganoids which gave rise to land vertebrates, the Tetrapoda, and to the air-breathing Dipnoans, on the one hand, and on the other to the family Saurichthyidae, through which they were related to the bony fishes, the Actinopterygians, to which so many modern fishes belong. In fact the cartilaginous ganoids of the later Paleozoic and earlier Mesozoic stood in a strategic position, giving rise to successful characters for all modern, osseous vertebrates, though they themselves failed, dying out either in late Jurassic or early Cretaceous time.

When Woodward published his Catalogue in 1891 more than twenty-five genera were assigned to the group of chondrostean fishes called the Paleoniscidae. The group is known from Europe and North America. Stensiö's memoir ('21) is largely devoted to the Paleoniscidae of the Triassic of Spitsbergen. No revision of the family has been published within recent years.

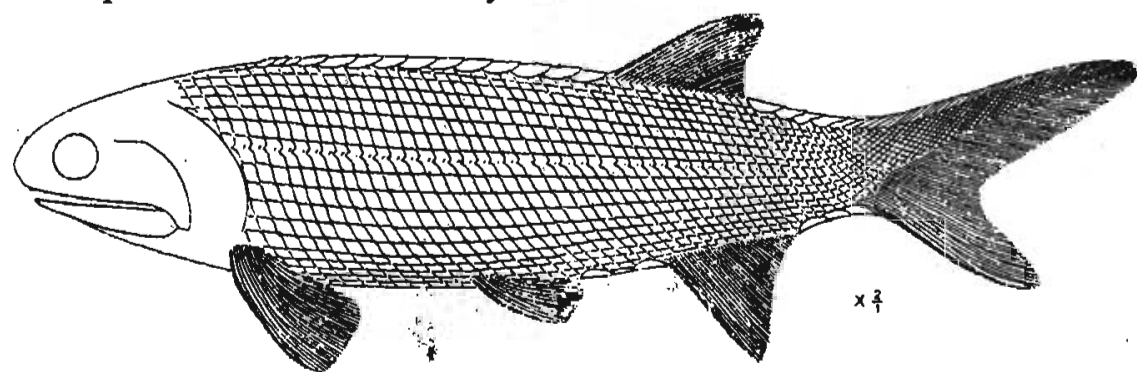

Fig. 80.-Restored outline of the body form, scutellation and fins of Rhadinichthys alberti (Jackson), a Paleoniscid ganoid from the Albert shales, Carboniferous, of New Brunswick, son), a Paleoniscid ganoid from the Albert shales, Carboniferous, of New Brunswick, It evidently swarmed in countless numbers in the waters of its time. In some of the beds numberless remains of fishes can be attributed to the occasional wholesale destruction of the fishes.-After Lambe.

One genus of the family, Rhadinichthys (Hussakof and Bryant, '18; Lambe, '10), is of especial interest (Figure 80 ) because a nodule 
containing the head of ${ }^{\circ}$ fish of this genus from the Mississippian of Kentucky furnished Eastman ('07) and Parker ('07) the material on which the earliest account of the brain was prepared.

The present specimen of a Paleoniscid may belong to the genus Rhadinichthys, but there are no characters on which we may base an identification. The nodule itself and the retained brain look like the nodules from the Coal Measures of Kansas (Moodie, '15). It is apparently not possible to say definitely what the geological age of the Iowa specimen is, but I believe it to have been derived from the Coal Measures.

The Paleoniscidae were all rather small fishes, the largest attaining a length of a few inches. Lambe ('10) has written a very splendid account of the conditions under which the Paleoniscidae of New Brunswick were preserved.

\section{The Nodules Containing the Brains}

The phosphatic nodules containing the paleoniscid brains are of a somewhat uniform appearance and apparently all have the same structure. None of them exceeds an inch and a half in length by threequarters inch in breadth. All are apparently derived from calcareous

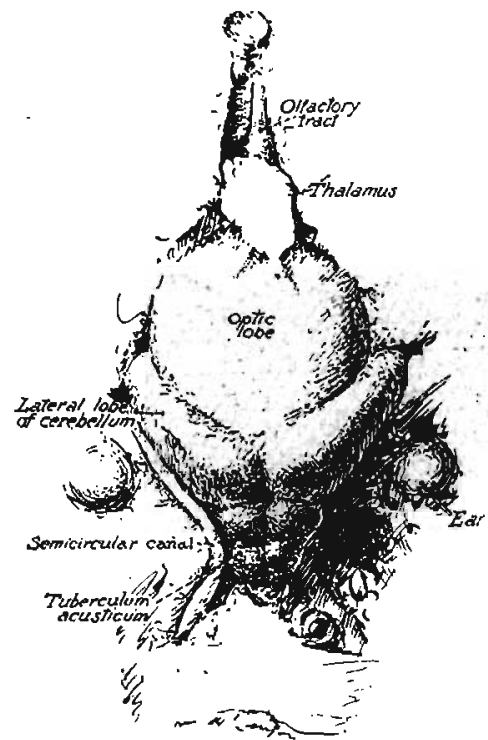

FIG. 81.-The oldest known fossil Paleoniscid brain, drawn with the aid of a reading glass from the original photograph, furnished by Dr. Eastman, natural size. of the speci. men of Rhadinichlihys deani Eastman, a ganoid from the Waverly shales, Mississippian, of Kentucky. The posterior part of the brain has been broken away. At the anterior tip of the olfactory tract is seen a poorly preserved enlargement which may represent the olfactory sac. Enlarged 2.5 times. 
shales. Their microscopic structure has been determined (Moodie, '20) but to this day no one knows why such brain-containing nodules refer exclusively to the single family, the Paleoniscidae. Nor has anyone explained why such perfect brains are preserved in these nodules. They are not casts, since I have shown that (Moodie, '20) there is a meningeal space filled with interlacing threads of calcite. So far as we know organic structures are not preserved within the brain substance. The present specimen shows a closer approximation of the brain to the brain case, but this is largely due to the fact that the ventral aspect of the brain is exposed, and it is natural to conclude that the inferior brain surface would more nearly approximate the meningeal wall than the superior surface, because of gravity.

\section{The Myodome}

The purpose of this section is to call more fully to attention the interesting observations and results of Dr. D. M. S. Watson ('25) on unpromising material-a small series of nodules from the Coal Measures of Kansas. He discovered, described and figured, for the first time, the myodome in the fossil family Paleoniscidae. The myodome was clearly functional and indicates the presence of large eyeballs in these small ancient fish. This is substantiated by my earlier (Moodie, '15) discovery of a large orbit, with a large optic nerve foramen leading into it.

The myodome is developed in response to the growth of the rectus muscle of the eye-ball. Its anatomy in recent fishes has been considered at length by Allis ('09, '19). This eye muscle canal of fishes has a counterpart among the higher vertebrates (Allis, '19) and while its occurrence in these Coal Measures fishes has undoubted evolutionary importance, yet its functional adaptation must not be lost sight of. The size and importance of the myodome is to be correlated with the optic lobe.

\section{The Nature of the Brain}

The brain of this ancient fish, as in most modern primitive fishes, is essentially a smelling and seeing organ, as is witnessed by the large size of the olfactory tract and the optic lobes (figures 81 and 82).

In spite of the great antiquity of the present specimen, dating as it probably does from the Coal Measures (figure 82), yet the brain is essentially actinopterygian. This means that although the Paleon- 
iscidae were ancient fishes of a primitive organization, they had nevertheless shown strong inclinations toward the bony fishes in such a manner as to exclude them from the stem forms which led to the higher vertebrates, the tetrapoda.

\section{Observations on the New Specimen}

The new specimen presents the following measurements:

Length of nodule .................. $26 \mathrm{~mm}$.

Width of nodule ................. $24 \mathrm{~mm}$.

Length of brain as preserved . . . . . . . . . .

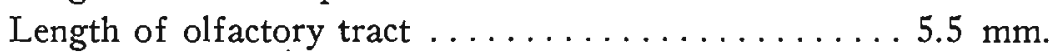

Length of optic lobe .............. $8 \mathrm{~mm}$.

Diameter of hypothalamus .............. $1 \mathrm{~mm}$.

Length of semicircular canals, as preserved ....... $10.5 \mathrm{~mm}$.

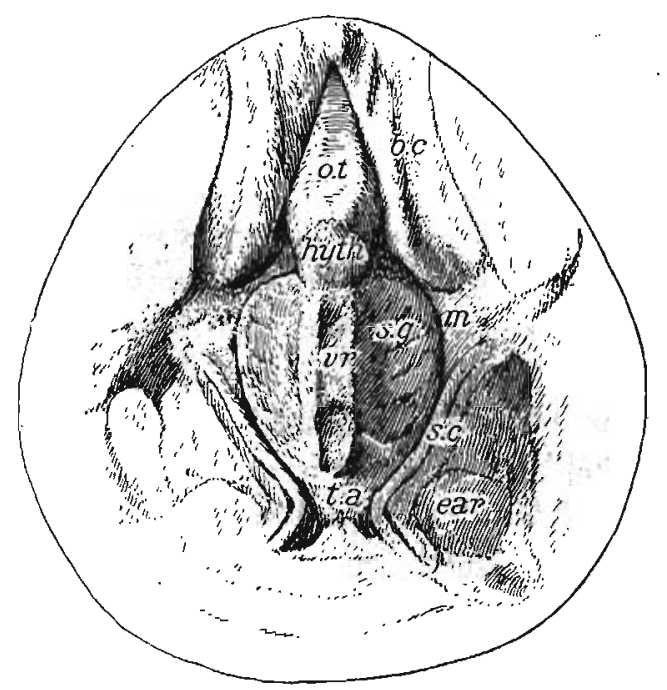

Frg. 82.-The new Paleoniscid brain from the Coal Measures (?) of Iowa. No. 13-338, Department of Geology, University of Iowa. The ventral aspect of the brain is shown anterior to the cerebellar region.

b. $c$. = brain case (cartilaginous?) represented :by very friable granular calcite.

ear=This rounded area, symmetrical on the two sides, may represent the position of the otoliths.

hyth =The nuclear enlargement doubtless represents the hypothalamus.

$m=$ The dark line to the left of the letter " $m$ " represents the thin meninges, greatly

$o$ reduced on the ventral a spect of the brain. The olfactory sac is bidden beneath the fossilized brain wall. Swelling of tract
The is unique.

s. $c$. = Semicircular canal, ventral aspect of a vertical canal, ending in ampullary enlargements, obvious only by careful examination under binocular microscope. Canals flattened, less than $1 \mathrm{~mm}$. in diameter.

s. $g$.=Primitive segmental grooves and ridges. Two narrow prominent ridges on right. t. a. =Structures ventral to tuberculum acusticum. (See figure 81.)

$v$. $r=$ Ventral ridge, broken. Broad $T$-shaped sweffing at the posterior end may represent the ventral continuation of the cerebellum.

Enlarged 2.5 times. 
It presents for consideration the ventral surface of the brain for the first time since these objects have received attention. The most obvious difference is in the absence of the prominent cerebellar lobes from the ventral surface. The broad $T$-shaped swelling of the posterior end of the ventral ridge (Fig. 82, v.r.) is assumed to indicate the ventral continuation of the cerebellum. Immediately posterior to this area there is a pronounced constriction and then a moderate expansion.

The optic lobes (Fig. 82) form the largest part of the brain structure preserved. Their ventral surfaces are marked with broad, shallow grooves and sharp, narrow primitive segmental ridges.

The ear is represented by parts of the anterior and posterior vertical semicircular canals on each side and a space which may have been occupied by the otolith (Fig. 82, ear). The canals are flattened and less than $1 \mathrm{~mm}$. in diameter. They end in poorly preserved ampullary enlargements. There is no evidence to show that the otic elements were any different from those of modern fishes.

The meningeal space is fairly narrow, except for such pockets as occur lateral to the hypothalamus (Fig. 82, hyth). The spaces throughout are filled with friable granular calcite. The ventral part of the meningeal spaces would necessarily be narrower than the dorsal, on account of the weight of the brain and the pull of the nerves.

The olfactory tract presents an appearance different "from that described in the case of the Kansas specimens (Moodie, '15). Both present a swelling, but the Kansas material shows this nuclear area to have been more localized. The terminal olfactory sac is not shown but doubtless lies below the fossilized brain case. Attempts to expose the sac by removing the friable material would have ended disastrously.

In all other respects the new brain specimen (Fig. 82) corresponds with those described from the Coal Measures (Moodie, '15).

It is possible that the elevation spoken of as the ventral ridge (figure 82 , v.r.) is not entirely neural in origin. A part of it may represent the endocranial cast of the floor of the brain case. The ridge itself is, however, so badly broken that this matter cannot be determined from this one specimen. 


\section{LIST OF WRITINGS CONSULTED DEALING WITH PRIMITIVE STURGEONS, OF THE FAMILY PALEONISCIDAE, AND THEIR BRAIN}

Abel, Othenio, 1919, Die Stämme der Wirbeltiere: Paleopiscidae, pp. 186-190, 3 figures. Literature.

Allis, E. P., 1909, Cranial Anatomy of the Mail-cheeked Fishes: Zoologica, 22, 1-219, 5 pls.

Allis, E. P., 1919, The Myodome and Trigemino-Facialis. Chamber of Fishes and the Corresponding Cavities in Higher Vertebrates: Journ. Morphol., 32, 207-326, 29 figures.

Dean, Bashford, 1923, A Bibliography of Fishes, Volume III, Brain, pp. 384-385. Family-Paleoniscidae, p. 622 .

Eastman, Charles R., 1907, Devonian Fishes of Iowa: Iowa Geol. Survey, xviii, 255-271, illus.

Eastman, Charles R., 1913, Brain Structures of Fossil Fishes from the Caney Shales : Bull. Geol. Soc. Amer., $24: 119$.

Eastman, Charles R,, 1917, Fossil Fishes in the Collection of the United States National Museum: Proc. U. S. Natl. Mus., 52, 235-304, 23 pls. Paleoniscidae, p. 273.

Hussakof, L, and Bryant, Wm. 1918, Catalog of the Fossil Fishes in the Museum of the Buffalo Society of Natural Sciences: Bull. Buffalo Soc. Natl. Sci., XII :1-346, jllus. Paleoniscidae, p. 181.

Lambe, Lawrence M., 1910, Paleoniscid Fishes from the Albert Shales of New Brunswick: Contrib. to Canadian Paleontology, Geol. Surv. Canada, Memoir No. 3, pp. 1-34, Plates I-XI.

1914, Description of a New Species of Platysomus from the Neighborhood of Banff, Alberta: Trans. Roy. Soc. Canada, 3d series, VIII: 17-23, illus.

Lambe, Lawrence M., 1916, Ganoid Fishes from near Banff, Alberta: Ibid., series iii, X, 35-44, illus.

Moodie, Roy L., 1915, A New Fish Brain from the Coal Measures of Kansas, with a Review of Other Fossil Brains: Journ. Comp. Neurol., xxv, No. 2, 135-181, Figs. 1-19, annotated bibliography. ..., 1920, Microscopic Examination of a Fossil Fish Brain: Ibid, xxxii, No. 3,2 figs.

Parker, G. H., 1907, Special Description of the Auditory Organs and Other Soft Parts: Iowa Geol. Surv., xviii, p. 272.

Stensio, Erik A., son, 1921, Triassic Fishes from Spitsbergen: Part I, Paleoniscidae, pp. 148-238, illus.

1925, Part II : Family Saurichthyidae, Brain, p. 176, Kungl. Svenska Vetenskapsakademiens, Handlingar, Tredje Serien, Band 2, No. 1.

See also his studies on the brain of the Cephalaspida in Downtownian memoir.

Watson, D. M. S., 1925, The Structure of Certain Palaeoniscids and the Relationships of that Group with Other Bony Fish: Proc. Zool. Soc. London, pp. $815-870,29$ Figures, 2 P1s.

.......... 1928, On Some Points in the Structure of Palaeoniscid and Allied Fish: Ibid., pp. 49-70, illus.

Woodward, A. Smith, 1891, Catalogue of the Fossil Fishes in the British Museum (Natural History): Paleoniscidae, Part II $: 424-526$, illus. 